\title{
Effect of Calcium Addition on the Inclusions Composition in the Cast Microstructure of HSLA Steel
}

\author{
Yan LIU ${ }^{1, a,{ }^{*}, \text { Kai WANG }}{ }^{2, b}$, Yang LIU ${ }^{2, c}$, Jian-Ming WANG ${ }^{2, d}$ \\ ${ }^{1}$ The Liaoning Provincial Key Laboratory of Advanced Materials \& Preparation Technology, \\ Shenyang University, Shenyang, 110044, China \\ ${ }^{2}$ School of Mechanical Engineering, Shenyang University, Shenyang 110044, China \\ aliuyanneu@163.com, bwkai1991@foxmail.com, cshendacaijialy@126.com, \\ dwjmlucky1979@163.com \\ ${ }^{*}$ Corresponding author
}

Keywords: Calcium, Cast Microstructure, Inclusions Composition, HSLA Steel.

\begin{abstract}
A new technology to obtain a fine-structured and high-toughness HAZ of HSLA steel for high heat input welding is developed using metallurgical thermodynamics, physical chemistry of metallurgy and material processing methods synthetically in this study. A kind of HSLA steel is designed in this experiment. The thermal stability second phase particles which would not be dissolved or aggregated at high temperature will be expected by means of adding calcium into the steel in the form of Si-Ca alloy. The effect of calcium addition on the morphology and compositions of the inclusions in the cast microstructure of HSLA steel was analyzed by using SEM and EDS. The results show that lots of calcium oxides and inclusions formed after pouring into ingots owing to the adding calcium element. The distribution of the inclusions is homogeneous, the size of the inclusions is even small, and most calcium inclusions are spherical and ellipsoidal. Adding calcium element in different amounts can lead to the large difference in the composition of the inclusions. The main components of the inclusions formed are calcium oxides and the composite inclusions, as well as the oxides, sulfides and composite inclusions of the other metallic elements.
\end{abstract}

\section{Introduction}

When the steel plates use the high heat input welding, the strength and toughness of the welding heat affected zone (HAZ) decreases with the increase of the heat input welding [1]. In such a situation, further enhancement of HAZ toughness and strength in structural steel plates has come to constitute important development subjects in order to insure the safety of steel structures [2]. Therefore, a new technology to obtain a fine-structured and high-toughness HAZ is developed for the purpose of realizing excellent toughness in a HAZ of HSLA steel for high heat input welding using metallurgical thermodynamics, physical chemistry of metallurgy and material processing methods synthetically. This is a technology whereby thermally stable oxides and sulfides containing $\mathrm{Ca}$ are dispersed in steel as fine particles. Calcium inclusions have high temperature stability, high melting point, ultra-fine, evenly distributed and controllable composition [3].

The experiment takes a kind of HSLA steel as the research object and analyses the effect of calcium addition on the morphology and composition of the inclusions in the cast microstructure. The study can provide a reliable theoretical basis and technical support for the development and application of high heat input welding HSLA steel which has good strength and toughness. The study can reduce production costs and save social resources effectively. The research results can transform into productivity and create a new growth point for the national economy.

\section{Experiments}

\section{Experimental Materials}

A kind of HSLA steel is designed in this experiment. The components of the steel are obtained by smelting pure iron and adding the corresponding alloy. The components of pure iron and main alloy 
are shown in Tab.1. Calcium is added in the form of Si-Ca alloy. Other alloys include electrolytic manganese (99.9\%), ferrovanadium (78.6\%), ferrotitanium (99\%), ferroniobium (65.6\%), ferronickel (78.6\%), ferrochromium (85.5\%) and molybdenum $(76.3 \%)$.

Tab.1 Components of pure iron and main alloys (wt $\%)$

\begin{tabular}{ccccccccccccc}
\hline Alloy & $\mathrm{C}$ & $\mathrm{Si}$ & $\mathrm{Mn}$ & $\mathrm{P}$ & $\mathrm{S}$ & $\mathrm{Al}$ & $\mathrm{Fe}$ & $\mathrm{Ca}$ & $\mathrm{Mg}$ & $\mathrm{Zr}$ & $\mathrm{Ni}$ & $\mathrm{Cu}$ \\
\hline $\begin{array}{c}\text { Pure } \\
\text { iron }\end{array}$ & 0.0013 & 0.01 & 0.05 & 0.007 & 0.0044 & 0.0013 & 92.6 & $/$ & $/$ & $/$ & $/$ & $/$ \\
$\mathrm{Fe}-\mathrm{Si}$ & 0.024 & 78.96 & 0.058 & 0.0093 & 0.0037 & 0.24 & 20.24 & $/$ & $/$ & $/$ & $/$ & 0.049 \\
$\mathrm{Si}-\mathrm{Ca}$ & 0.13 & 66 & $/$ & 2.6 & $/$ & 0.15 & $/$ & 31 & $/$ & $/$ & $/$ & 12 \\
\hline
\end{tabular}

\section{Smelting Equipment and Process}

The experimental steel was smelted in BJ-VIM-5 vacuum induction melting furnace. Main performance parameters of vacuum induction melting furnace were shown in Tab.2.

Tab.2 Main performance parameters of BJ-VIM-5 vacuum induction melting furnace

\begin{tabular}{cc}
\hline Main parameters & values \\
\hline Rated capacity $(\mathrm{kg})$ & 5 \\
Ultimate vacuum $(\mathrm{Pa})$ & $6.67 \times 10^{-3}$ \\
Maximum working temperature $\left({ }^{\circ} \mathrm{C}\right)$ & 1750 \\
Power capacity $(\mathrm{kW})$ & 30 \\
Pressure rise rate $(\mathrm{Pa} / \mathrm{h})$ & $\leq 2$ \\
\hline
\end{tabular}

The directions of the microalloyed development in HSLA steel in every country throughout the world are as follows: (1) The obvious trend of carbon reduction presents. (2) The microalloy method combines with the thermo mechanical control process (TMCP). Use the composite microalloy $(\mathrm{Nb}, \mathrm{V}, \mathrm{Ti})$ to produce grain refinement and precipitation strength [4]. Therefore, that is widely used [5]. Ca and $\mathrm{Mg}$ metallic elements are added to form high smelting-point oxides, improving toughness and weldability of the steel plate. We designed a kind of HSLA steel, based on the above principle and absorbing predecessors's research experiences.

The four furnaces in the test were accomplished in the order of no calcium addition, $1 \mathrm{wt} \% \mathrm{Ca}$ addition, $3 \mathrm{wt} \% \mathrm{Ca}$ addition and $5 \mathrm{wt} \% \mathrm{Ca}$ addition.

The steps of smelting the experimental steel are as follows. (1) The raw materials are put into the crucible. We must adopt the principle of tightness below and looseness above in order to make the smelting process go smoothly, when we add the raw materials. (2) After adding the raw materials, we begin to vacuumize. When the vacuum degree reaches $1.0 \times 10^{-2} \mathrm{~Pa}$, we begin to heat. (3) We turn up the power gradually in the heating process until the raw materials melt totally. (4) The argon gas as protective gas is filled in the whole smelting process to prevent the raw materials from oxidating. When the steel boils, we add alloy by a special method. (5) After adding alloy, we begin to stir it. After refinement for several minutes, we turn off the heating equipment and begin to pour. (6) After cooling for three hours, the casting mould is taken out.

\section{Effect of Calcium Addition on the Inclusions Composition in the Cast Microstructure of the HSLA Steel}

\section{The Morphology and Composition of the Inclusions in the Cast Microstructure}

The scanning electron microscope (SEM) and energy dispersive spectrometer (EDS) were used to analyze the morphology and composition of the inclusions in the cast microstructure of the HSLA 
steel. The morphology and composition of the inclusions in the cast microstructure of the 1-4\# experimental steel are respectively shown in Fig.1.

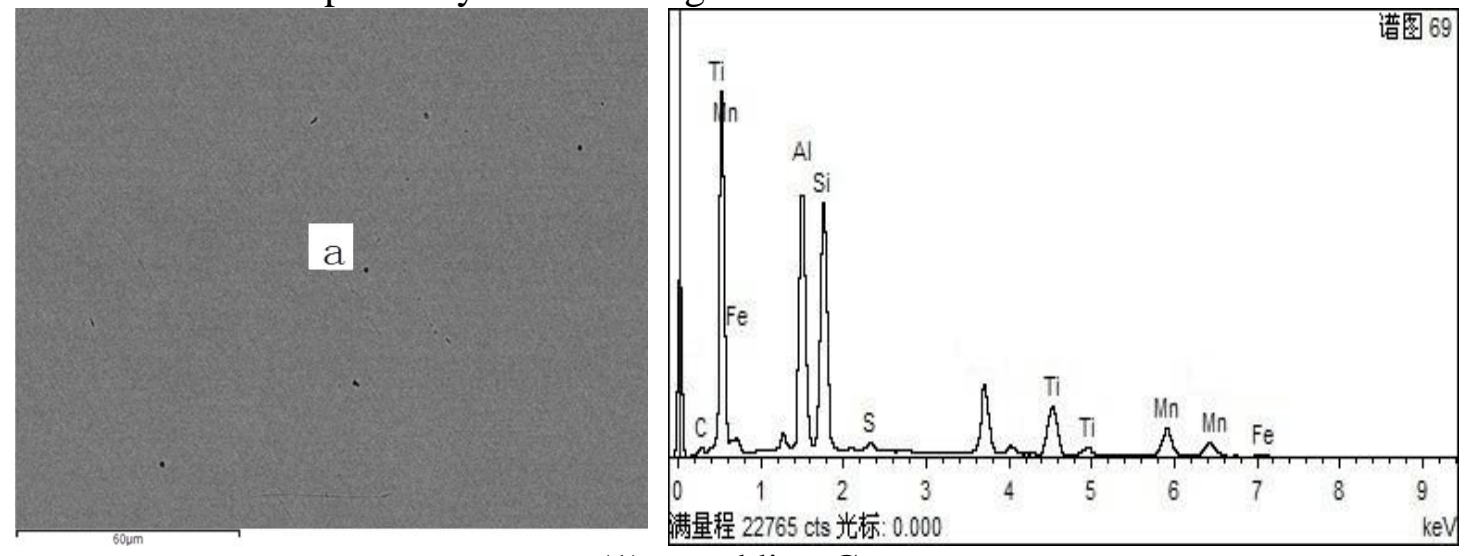

(1) no adding $\mathrm{Ca}$
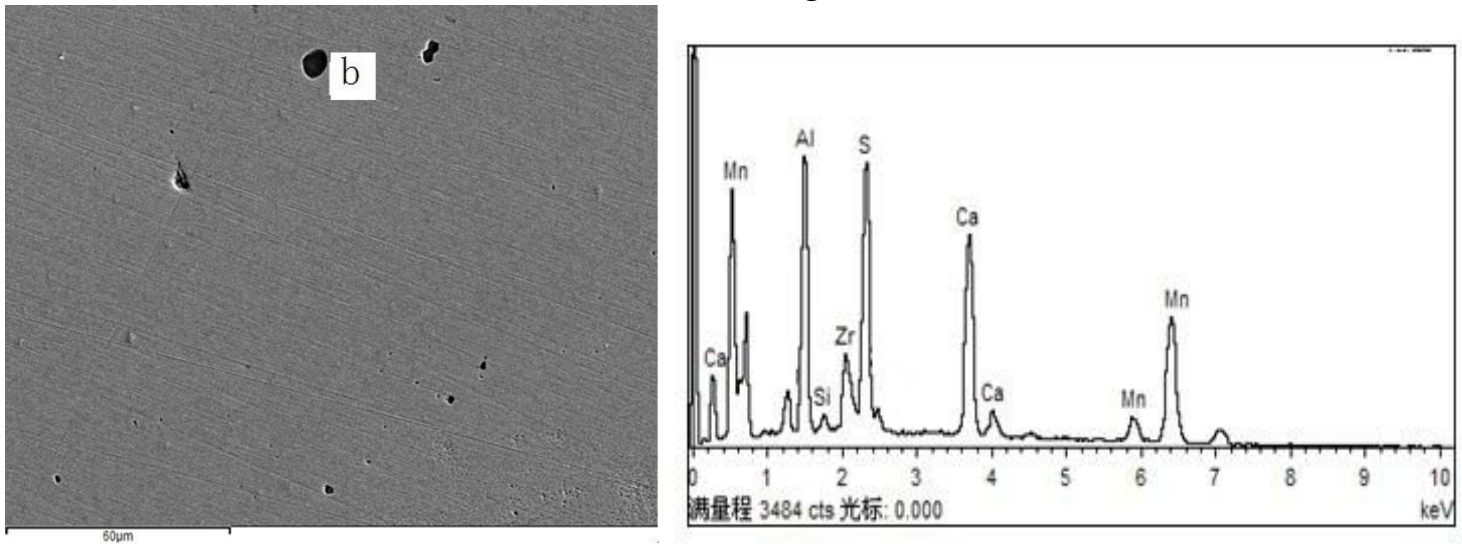

(2) $1 \mathrm{wt} \% \mathrm{Ca}$

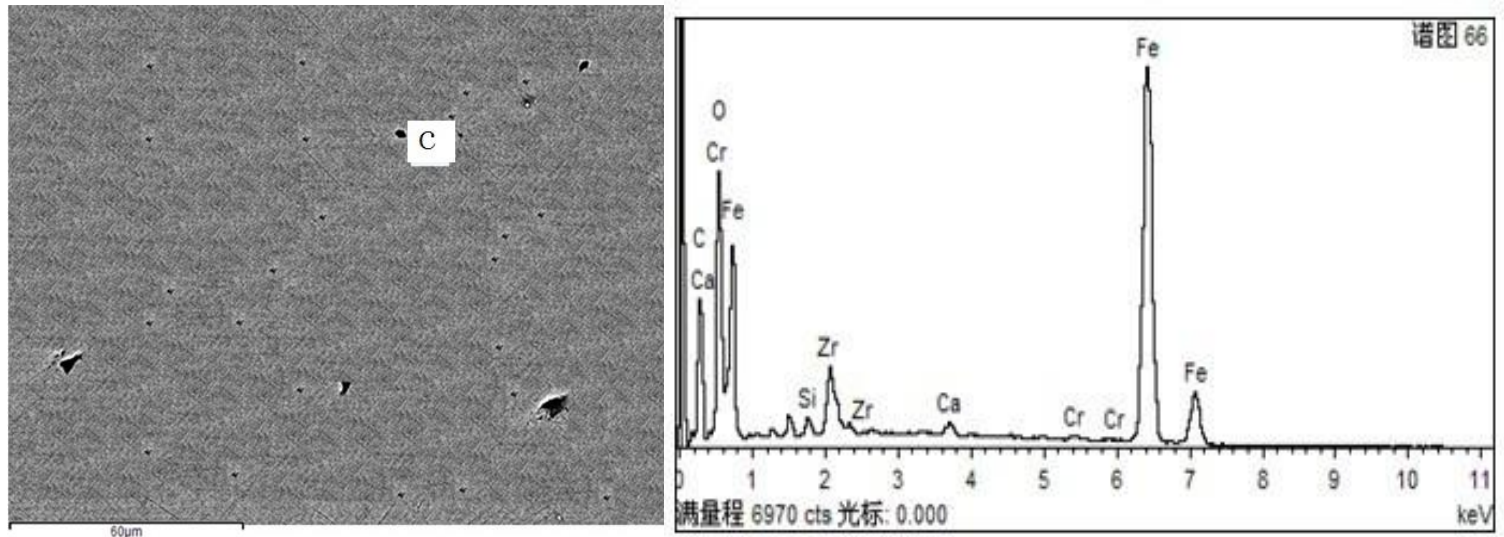

(3) $3 \mathrm{wt} \% \mathrm{Ca}$

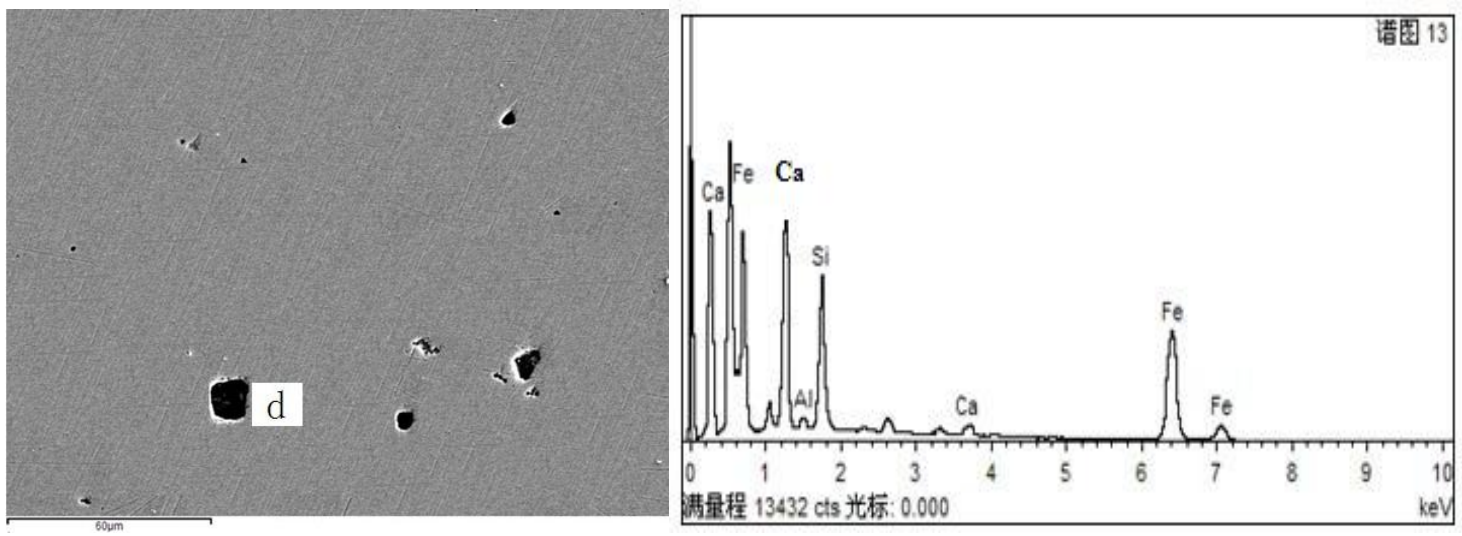

(4) $5 \mathrm{wt} \% \mathrm{Ca}$

Fig. 1 The morphology and composition of the inclusions in each sample 


\section{Results Analysis}

From SEM and EDX analysis results, adding $\mathrm{Ca}$ element in different amounts can lead to the large differences in the type, quantity, composition and distribution of the inclusions. The specific analysis is shown in Fig.1.

Through the contrast analysis to the morphology of the inclusions in the samples, we can find that after adding $\mathrm{Ca}$ element, the distribution of the inclusions is more dense and uniform with respect to the raw steel, and the size of the inclusions is smaller than the ones in the raw steel.

Fig.1 (1) is the figure of the electron backscatter diffraction (EBSD) and EDS in the raw steel, the inclusions are mainly the $\mathrm{TiO}_{\mathrm{X}}-\mathrm{Al}_{2} \mathrm{O}_{3}-\mathrm{SiO}_{2}-\mathrm{MnS}$ composite ones. Fig.1 (2) is the figure of the EBSD and EDS in $1 \mathrm{wt} \% \mathrm{Ca}$ steel, the inclusions are mainly $\mathrm{Al}_{2} \mathrm{O}_{3}-\mathrm{MnS}-\mathrm{CaO}-\mathrm{ZrO}_{2}-\mathrm{SiO}_{2}$. Fig.1 (3) is the figure of the EBSD and $\mathrm{EDS}$ in $3 \mathrm{wt} \% \mathrm{Ca}$ steel, the inclusions are mainly $\mathrm{ZrO}_{2}-\mathrm{CaO}-\mathrm{SiO}_{2}-\mathrm{CrOx}$. Fig.1 (4) is the figure of the EBSD and EDS in $5 \mathrm{wt} \% \mathrm{Ca}$ steel, the inclusions are mainly $\mathrm{CaO}-\mathrm{SiO}_{2}-\mathrm{Al}_{2} \mathrm{O}_{3}$.

In a word, the study found that lots of $\mathrm{Ca}$ oxides and inclusions formed after pouring into ingots owing to the adding $\mathrm{Ca}$ element. The distribution of the inclusions is homogeneous, the size of the inclusions is even small, and most $\mathrm{Ca}$ inclusions are spherical and ellipsoidal. Adding $\mathrm{Ca}$ element in different amounts can lead to the large difference in the composition of the inclusions.

\section{Conclusions}

Calcium element was added into molten steel in the form of Si-Ca alloy in the experiment. The experiment takes a kind of HSLA steel as the research object and analyzes the effect of calcium addition on the morphology and composition of the inclusions in the cast microstructure of the HSLA steel by using SEM and EDX analysis.

(1) Adding Ca element in different amounts can lead to the large differences in the type, quantity, composition and distribution of the inclusions.

(2) Through the contrast analysis to the morphology of the inclusions in the samples, we can find that after adding $\mathrm{Ca}$ element, the distribution of the inclusions is more dense and uniform with respect to the raw steel, and the size of the inclusions is smaller than the ones in the raw steel.

(3) Lots of $\mathrm{Ca}$ oxides and inclusions formed after pouring into ingots owing to the adding $\mathrm{Ca}$ element. The main components of the inclusions formed are calcium oxides and the composite inclusions, as well as the oxides, sulfides and composite inclusions of the other metallic elements. And most calcium inclusions are spherical and ellipsoidal.

\section{Acknowledgments}

This work was supported by the Liaoning Province Natural Science Fund Project (No. 2014020097), the Project for Liaoning Provincial Scientific Research in University of China (No. L2014475) and the Open Subject Fund of the State Key Laboratory of Rolling and Automation of NEU, China (No. 2009003).

\section{References}

[1]W. Shu, X.M. Wang, S.R. Li, Nucleation and growth of intragranular acicular ferrite and its effect on grain refinement of the heat-affected-zone, Acta Metallurgica Sinica. 47 (2011) 435-441.

[2]A. Kojima, A. Kiyose, R. Uemori, Super high HAZ toughness technology with fine microstructure imparted by fine particles, Nippon Steel Technical Report. 380 (2004) 2-6.

[3]F. Chai, C. F. Yang, H. Su, Effect of magnesium on inclusion formation in Ti-killed steels and microstructural evolution in welding induced coarse-grained heat affected zone, Journal of Iron and Steel Research, International. 16 (2009) 69-74.

[4]Y.T. Chen, A.M. Guo, P.H. Li, Nitride and carbonitride precipitation behavior in a Nb-Ti 
microalloyed extra low carbon HSLA steel, Heat Treatment of Metals. 32 (2007) 51-54.

[5]Y. Li, C.X. Wang, Z.L. Tian, Investigation on microstructure and mechanical properties of a low alloyed ultra-high strength steel, Iron and Steel. 43 (2008) 75-79. 